Article

\title{
Numerical Study on the Working Performance of a Streamlined Annular Jet Pump
}

\author{
Xiaodong Wang, Yunliang Chen *, Mengqiu Li, Yong Xu, Bo Wang and Xiaoqiang Dang \\ State Key Laboratory of Hydraulics and Mountain River Engineering, Sichuan University, \\ Chengdu 610065, China; xiaodongwang2222@163.com (X.W.); 13031333898@163.com (M.L.); \\ yongxu@scu.edu.cn (Y.X.); wb9943065021@163.com (B.W.); nike0680@163.com (X.D.) \\ * Correspondence: chenyunliang@scu.edu.cn; Tel.: +86-135-4129-1332
}

Received: 24 July 2020; Accepted: 24 August 2020; Published: 26 August 2020

\begin{abstract}
To improve the working performance of the early annular jet pump (EAJP), a streamlined annular jet pump (SAJP) was proposed. The flow field and working performance of the EAJP and SAJP with an area ratio $(m)$ of 1.75 were numerically studied and compared, separately, by using the combination of the Realizable $k-\varepsilon$ turbulence model and the Schnerr-Sauer cavitation model. The results show that the efficiency of the SAJP is higher than that of the EAJP, when the flow ratio $(q)$ is higher than 0.30 , with a maximum increase of $1.2 \%$. Furthermore, the high-efficiency area of the SAJP $(q=0.40 \sim 0.69)$ is wider than that of the EAJP $(q=0.36 \sim 0.57)$. There is no flow separation and low local pressure in the SAJP, due to the conjunction part of the suction chamber, throat, diffuser and outlet pipe without the structural mutation. It was found that the incipient cavitation number $\left(\sigma_{i}\right)$ of the SAJP and EAJP was 0.541 and 0.578 , respectively; therefore, the cavitation performance of the SAJP is better. Meanwhile, the critical flow ratio $\left(q_{c}\right)$ of the SAJP is 0.69 , which is larger than that of the EAJP $\left(q_{c}=0.57\right)$, implying that the SAJP has a wider normal working range than the EAJP. Importantly, the inception and development of cavitation appeared in the diffuser of the SAJP, different from that in the throat of the EAJP. Hence, it concluded that the cavitation in the SAJP has less influence on the flow field and working performance.
\end{abstract}

Keywords: annular jet pump; streamlined profile; numerical simulation; incipient cavitation number; critical flow ratio

\section{Introduction}

The jet pump is used in energy, water conservancy, civil engineering and other fields due to the advantages of easy operation and simple construction [1-3]. Wiesche et al. [4] numerically studied the cavitation performance of the jet pump when it was applied to an automobile fuel system. Yin et al. [5] analyzed the application of the jet pump in the city central heating system and compared the operation energy consumption of the original heating systems and the injection pump. Liu et al. [6] studied the energy-saving effect of the jet pump applied in the heating system and pointed out that the jet pump obtained good energy-saving and economic benefits. There are two most common types of jet pumps, namely the central jet pump (CJP) and the annular jet pump (AJP). An AJP is mainly composed of an annular nozzle, a suction chamber, a throat and a diffuser (Figure 1). It can be seen that the entrained flow is surrounded by the annular primary flow and the flow passage is unobstructed in the AJP. Therefore, the AJP can be used in the transportation of liquid which contains large solid particles, e.g., onions, fish, potatoes and capsules [7-9]. Similar to other types of pumps [10,11], the working performance of the AJP is mainly composed of traditional performance and cavitation performance, and the flow field and cavitation characteristics are important factors affecting its 
performance. Hence, it is of great significance to study the flow field and cavitation of the AJP and improve its working performance.

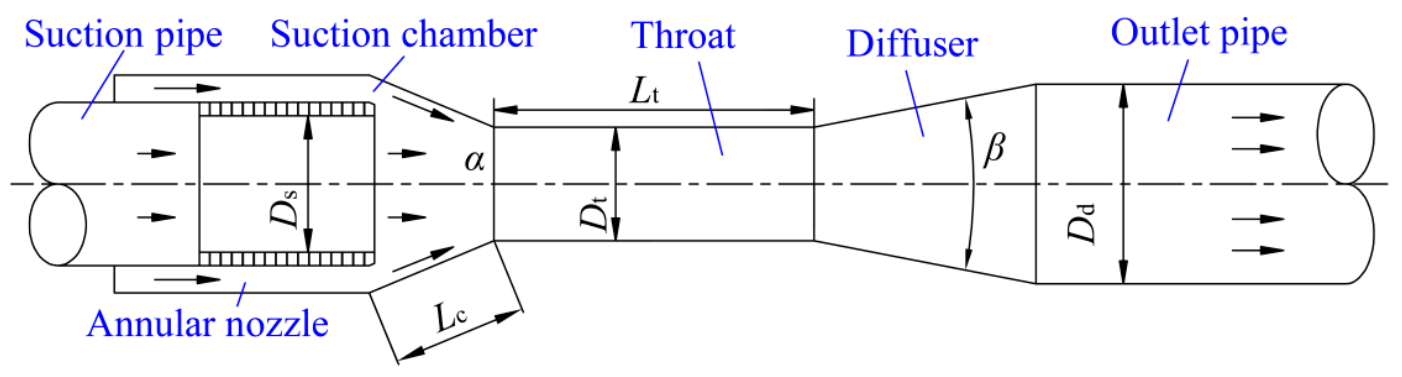

Figure 1. Early annular jet pump (EAJP).

Research has been carried out on the influence of structural parameters of the AJP on its traditional performance, including the inclined angle of the suction chamber $(\alpha)$, area ratio $(m)$, throat length and included angle of the diffuser ( $\beta$ ). For example, Kwon et al. [12] studied the effect of the inclined angle of the suction chamber $(\alpha)$ on pump performance at different flow ratios by using the numerical method. It was found that the efficiency $(\eta)$ was highest when $\alpha=12^{\circ}$. Long et al. [13] analyzed the influence of throat length, $\alpha$ and $\beta$ on pump performance, with the method of DOE (the design of experiment method) and CFD (computational fluid dynamics), and obtained the optimal structure of the AJP: $\alpha$ was $15^{\circ}$, relative throat length was 2.45 and $\beta$ was $4^{\circ}$. Yang et al. [14] proposed two kinds of diffuser designs based on the constant rate of velocity/pressure change method (CRVC/CRPC) and pointed out that the AJP with the CRVC/CRPC diffuser displays better performance when the included angle of diffuser is greater.

In the studies on the cavitation performance of the AJP, Shimizu et al. [15] conducted a large number of experimental studies on 25 groups of annular jet pumps with different throat lengths, $m$ and $\alpha$, and analyzed the influence of different structure sizes on the cavitation performance of the AJP. In the studies by Xiao et al. [16], the influence of $\alpha$ on the cavitation performance of the AJP was analyzed, and they found that the cavitation performance of the AJP was optimal when $\alpha$ was $20^{\circ}$. The later works by Xiao et al. $[17,18]$ further studied the transient pulse characteristics of cavitating flow in the AJP. They pointed out that the cavitating flow in the AJP can be classified into three types: cavitating flow in the recirculation, cavitating flow in the shearing layer and cavitation induced by the flow separation, based on the cavitation mechanisms. Furthermore, the high-speed camera was used to observe the recirculation region and various types of cavity clouds. It was found that three types of cavity clouds appeared successively, namely, ribbon-like, annular and merged cavity.

Since the high-velocity primary flow usually flows along the inner wall surface of the pump, the geometry of the suction chamber, throat and diffuser might have a great influence on the working performance and flow field of the AJP. In the early annular jet pump (EAJP), the suction chamber, throat and diffuser are conical, cylinder and conical, respectively, as shown in Figure 1. There are several shortcomings of this geometry of the EAJP [19]. For example, the abrupt structure change at the throat and diffuser inlet will lead to the local head loss and flow separation; the flow separation will further induce the cavitation occurrence. Unfortunately, there are few relevant studies on the structure optimization of the EAJP to improve its working performance, especially the cavitation performance.

Herein, to optimize the flow field and improve the working performance of the EAJP, a streamlined annular jet pump (SAJP) was proposed in this study, as shown in Figure 2. It can be seen that no abrupt structure change appeared in the SAJP. The high-velocity primary flow could flow smoothly in the pump without the occurrence of flow separation, reducing energy loss and eliminating the low local pressure. Based on the numerical method which combines the Realizable $k-\varepsilon$ turbulence model and the Schnerr-Sauer cavitation model, the flow fields of the EAJP and SAJP were simulated. Furthermore, 
the differences in the traditional performance and cavitation performance of the EAJP and SAJP were analyzed in this study.

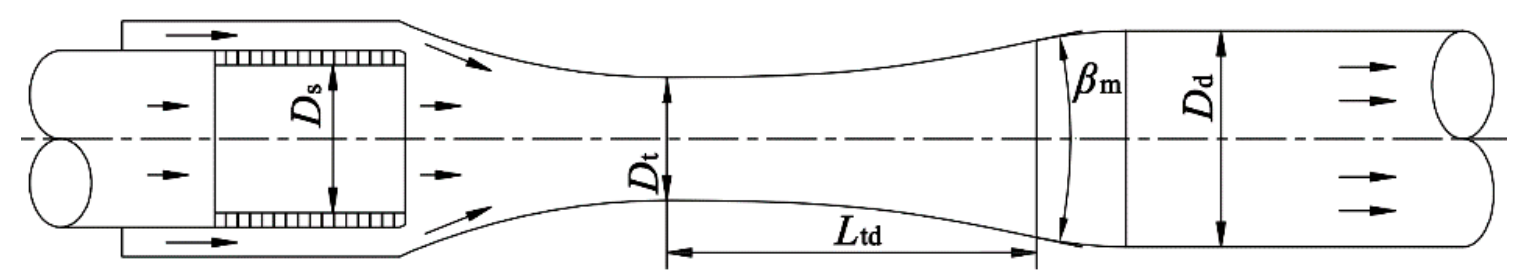

Figure 2. Streamlined annular jet pump (SAJP).

\section{Numerical Method}

\subsection{Physical Model}

The EAJP with maximum efficiency in [15] was chosen as the model pump in this study. Table 1 shows the dimensions of the chosen EAJP. The accuracy of the numerical method will be verified by comparing the numerical results with the experimental results from Shimizu et al. [15].

Table 1. Dimensions of the EAJP.

\begin{tabular}{ccccccc}
\hline$D_{\mathbf{s}}(\mathbf{m m})$ & $\boldsymbol{\alpha}\left({ }^{\circ}\right)$ & $\boldsymbol{L}_{\mathrm{c}}(\mathbf{m m})$ & $\boldsymbol{D}_{\mathbf{t}}(\mathbf{m m})$ & $\boldsymbol{L}_{\mathrm{t}}(\mathbf{m m})$ & $\boldsymbol{\beta}\left({ }^{\circ}\right)$ & $\boldsymbol{D}_{\mathrm{d}}(\mathbf{m m})$ \\
\hline 43 & 18 & 54.4 & 38 & 102.3 & 5.8 & 55 \\
\hline
\end{tabular}

The SAJP with $m=1.75$ was designed based on the model pump, and the design idea is as follows: replacing the original profile of suction, throat and diffuser with the streamlined profile. As shown in Figure 3, the blue and red lines show the profile of the EAJP and SAJP, respectively. The profile of the SAJP is composed of two segments, A and B, which are connected smoothly. The profile in segment $\mathrm{A}$ is an arc-shape line, in which the central angle is $\alpha / 2$ and the upstream and downstream are tangent to the inner wall of the annular nozzle and the beginning of the profile of segment $B$, separately. The profile in segment $B$ was designed based on the power function, and the end of the profile is smoothly connected with the inner wall of the outlet pipe by an arc profile.

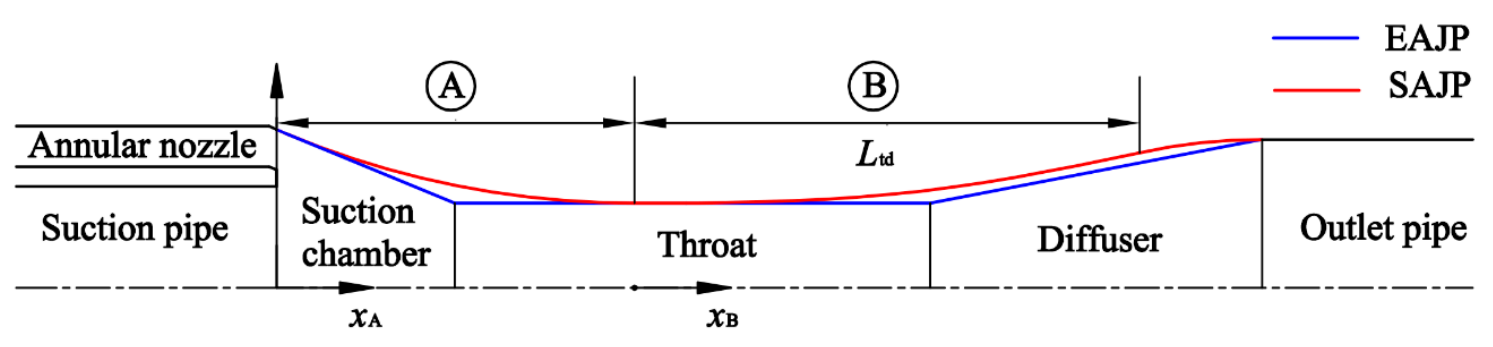

Figure 3. Profiles of the EAJP and SAJP.

The equation of the profile in segment $\mathrm{A}$ is as follows:

$$
R\left(x_{\mathrm{A}}\right)=\left[\frac{D_{\mathrm{t}}}{2}+L_{\mathrm{c}} \times \cot \left(\frac{\alpha}{4}\right)\right]-\sqrt{\left[L_{\mathrm{c}} \times \cot \left(\frac{\alpha}{4}\right)\right]^{2}-\left\{x_{\mathrm{A}}-L_{\mathrm{c}}\left[1+\cos \left(\frac{\alpha}{2}\right)\right]\right\}^{2}}
$$

where $R\left(x_{\mathrm{A}}\right)$ is the radius of the inner wall in segment $\mathrm{A} ; x_{\mathrm{A}}$ is the axial coordinate of the profile in segment $\mathrm{A}, 0<x_{\mathrm{A}}<L_{\mathrm{C}}[1+\cos (\alpha / 2)] ; L_{\mathrm{c}}$ and $\alpha$ are the length and inclined angle of suction chamber; and $D_{\mathrm{t}}$ is the diameter of throat. 
The equation of the profile in segment B is as follows:

$$
R\left(x_{\mathrm{B}}\right)=\frac{D_{\mathrm{t}}}{2} \times\left[1+k\left(\frac{x_{\mathrm{B}}}{L_{\mathrm{td}}}\right)^{n}\right]
$$

where $R\left(x_{\mathrm{B}}\right)$ is the radius of the inner wall in segment $\mathrm{B} ; x_{\mathrm{B}}$ is the axial coordinate of the profile in segment $\mathrm{B}, 0<x_{\mathrm{B}}<L_{\mathrm{td}} ; L_{\mathrm{td}}$ is the total axial length of the profile in segment $\mathrm{B}$ and set as $5.5 D_{\mathrm{t}}$ $\left(L_{\mathrm{td}}=4 \sim 7 D_{\mathrm{t}}\right) ; k$ is a coefficient related to $D_{\mathrm{d}} / D_{\mathrm{t}} ; n$ is the exponent and set as $3(n=2.5 \sim 5)$. The value range of the included angle $\left(\beta_{\mathrm{m}}\right)$, at the ending of the profile (Section $\mathrm{B}$ ), can be determined as $8 \sim 12^{\circ}$ based on the above parameters, and this study was about $12^{\circ}$.

\subsection{Governing Equations}

In the numerical study of the jet pump, the calculation domain was usually set as two-dimensional (2D) axisymmetric, due to the rotational symmetry of the jet pump. Kwon et al. [12] studied the influence of the geometry of the suction chamber on the performance of the EAJP based on the 2D axisymmetric model and found that the numerical results were well consistent with the experimental results. Xiao et al. $[17,20]$ used the $2 \mathrm{D}$ axisymmetric model to calculate the cavitating flow in the annular jet pump. The results show that the 2D simplified model results are in good agreement with the experimental results. Xiao et al. [21] simulated the cavitation in the central jet pump based on the 2D axisymmetric model and pointed out that the cavitation bubbles firstly appear near the tips of the nozzle, which is consistent with the position observed in the experiment. Therefore, the 2D axisymmetric model was used to take the three-dimension (3D) effect into account in this study. Since the circular jet and flow separation can be well simulated by the Realizable $k-\varepsilon$ turbulence model, and the cavitating flow in the AJP is mainly cloud and sheet cavitation, the Realizable $k-\varepsilon$ turbulence model combining the Schnerr-Sauer model and the Mixture model was applied in simulation. Meanwhile, the accuracy of the above numerical method has been validated by relevant researches [20,22].

In the Mixture multiphase model, the continuity and momentum equations for the mixture are:

$$
\begin{gathered}
\frac{\partial \rho_{m}}{\partial t}+\frac{\partial\left(\rho_{m} u_{j}\right)}{\partial x_{j}}=0 \\
\frac{\partial\left(\rho_{m} u_{i}\right)}{\partial t}+\frac{\partial\left(\rho_{m} u_{i} u_{j}\right)}{\partial x_{j}}=-\frac{\partial p}{\partial x_{i}}+\rho_{m} f_{i}+\frac{\partial}{\partial x_{j}}\left[\left(\mu+\mu_{t}\right)\left(\frac{\partial u_{i}}{\partial x_{j}}+\frac{\partial u_{j}}{\partial x_{i}}-\frac{2}{3} \frac{\partial u_{k}}{\partial x_{k}} \delta_{i j}\right)\right]
\end{gathered}
$$

where $u_{i}$ and $f_{i}$ are the velocity and body force of $i$ direction, $p$ is the pressure of mixture, $\mu$ is the viscosity of molecular and $\mu_{t}$ is the viscosity of turbulent. The density of mixture $\left(\rho_{m}\right)$ is:

$$
\rho_{m}=\alpha_{v} \rho_{v}+\left(1-\alpha_{v}\right) \rho_{l}
$$

where $\alpha_{v}$ is the volume fraction of vapor phase, $\rho_{v}$ is the density of vapor and $\rho_{l}$ is the density of liquid.

In the Schnerr-Sauer cavitation model, the number of bubbles per volume of liquid $\left(n_{b}\right)$ and $\alpha_{v}$ can be coupled by using the following equation:

$$
\alpha_{v}=\left(\frac{4}{3} n_{b} \pi R_{B}^{3}\right)\left(1+\frac{4}{3} n_{b} \pi R_{B}^{3}\right)^{-1}
$$

where $R_{B}$ is the radius of bubble. The liquid-vapor mass transfer (evaporation and condensation) is governed by the vapor transport equation:

$$
\frac{\partial}{\partial t}\left(\alpha_{v} \rho_{v}\right)+\nabla \cdot\left(\alpha_{v} \rho_{v} \vec{V}\right)=\dot{m}^{+}-\dot{m}^{-}
$$


where $\dot{m}^{+}$and $\dot{m}^{-}$are the source terms of mass transfer related to the growth and collapse of vapor bubbles, respectively.

Neglecting the effect of surface tension and the second-order terms, the Rayleigh-Plesset equation [23] can be expressed as:

$$
\frac{d R_{B}}{d t}=\sqrt{\frac{2}{3} \frac{\left|p_{v}-p\right|}{\rho_{l}}}
$$

where $p_{v}$ is the saturated vapor pressure ( $-97.785 \mathrm{kPa}$ in this study, relative pressure). Combining Equations (6)-(8), the source terms $\dot{m}^{+}$and $\dot{m}^{-}$can be defined as when $p>p_{v}$

$$
\dot{m}^{-}=\frac{\rho_{v} \rho_{l}}{\rho} \alpha_{v}\left(1-\alpha_{v}\right) \frac{3}{R_{B}} \sqrt{\frac{2}{3} \frac{\left(p_{v}-p\right)}{\rho_{l}}}
$$

when $p>p_{v}$

$$
\dot{m}^{+}=\frac{\rho_{v} \rho_{l}}{\rho} \alpha_{v}\left(1-\alpha_{v}\right) \frac{3}{R_{B}} \sqrt{\frac{2}{3} \frac{\left(p-p_{v}\right)}{\rho_{l}}}
$$

The coupling of the velocity and pressure was solved by s coupled algorithm, and the equations of turbulent kinetic and momentum were discretized by the second-order upwind scheme. Moreover, the pressure and transport equation of vapor mass fraction were discretized by the PRESTO! and Quick schemes, separately. The scalable wall function was applied to solve the near-wall area, and the time step was $10^{-5} \mathrm{~s}$. All of the numerical calculations were carried out under a relative pressure system (operating pressure was $101.325 \mathrm{kPa}$ ).

\subsection{Mesh and Boundary Conditions}

The calculation domain, as shown in Figure 4a, comprised a suction pipe, an annular nozzle, a suction chamber, a throat, a diffuser and an outlet pipe. The $x$ direction was downstream, and the origin was set at the nozzle outlet; the $r$ was radial. To ensure a stable flow, the length of the suction pipe and outlet pipe were lengthened $5 D_{\mathrm{s}}$ and $5 D_{\mathrm{d}}$, separately [24].

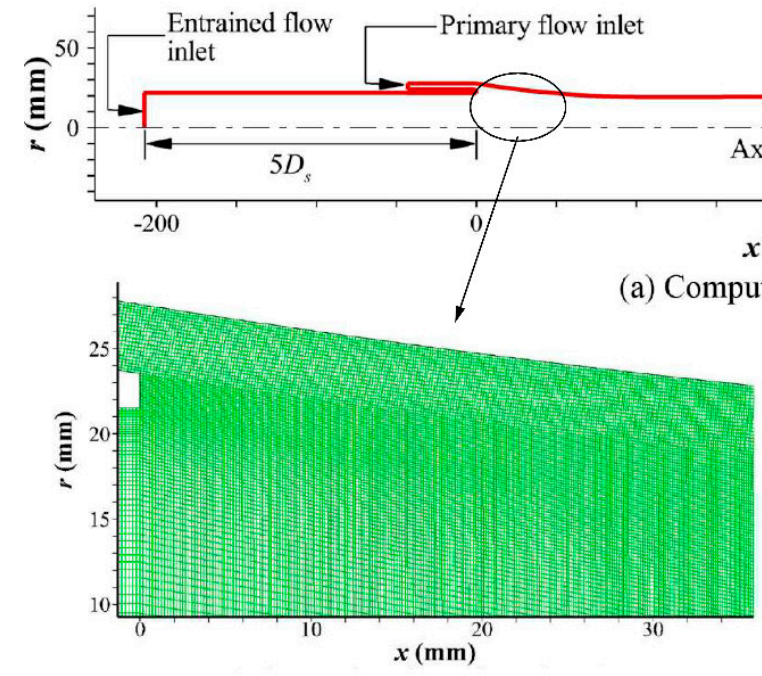

(b) Suction chamber

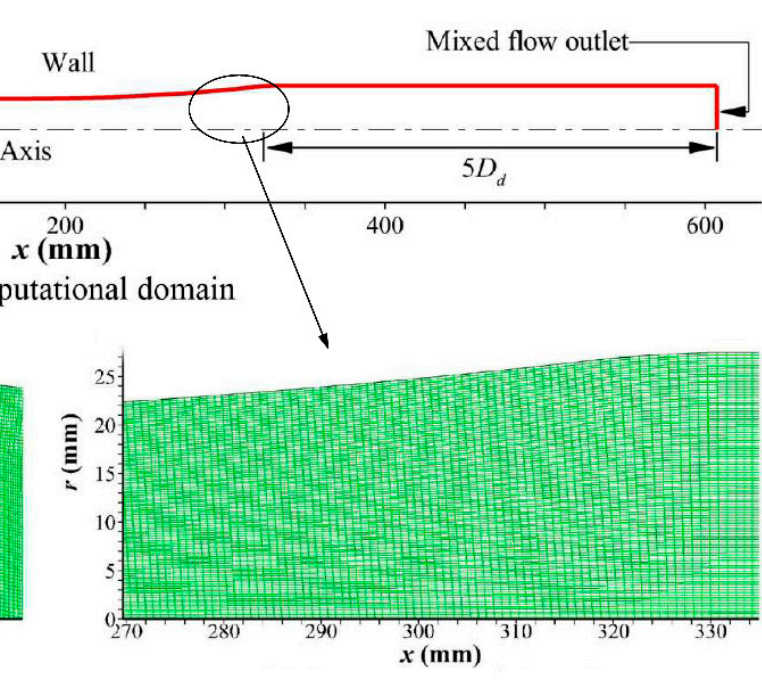

(c) Diffuser

Figure 4. Computational domain and local mesh.

The primary flow flows out from the annular nozzle and mixes with the entrained flow in the suction chamber. Since the mixing process is always accompanied by intensive turbulence shearing, the mesh of the suction chamber was refined, as shown in Figure $4 \mathrm{~b}$. 
The primary and entrained flow inlet were both set as velocity inlet, and the mixed flow outlet was set as pressure outlet. The axis and the wall were axisymmetric and no-ship, separately. In the calculation, the velocity of the primary flow was kept constant, and different flow ratio conditions were obtained by changing the velocity of the entrained flow.

\subsection{Simulation Validation}

The performance parameters of the AJP, including area ratio $(m)$, flow ratio $(q)$, pressure ratio $(h)$ and efficiency $(\eta)$, are defined as follows [15]:

$$
\begin{gathered}
m=\frac{A_{\mathrm{t}}}{A_{\mathrm{j}}} \\
h=\left(H_{\mathrm{c}}-H_{\mathrm{s}}\right) /\left(H_{\mathrm{j}}-H_{\mathrm{c}}\right) \\
q=\frac{Q_{\mathrm{s}}}{Q_{\mathrm{j}}} \\
\eta=q h
\end{gathered}
$$

where $A_{\mathrm{t}}$ and $A_{\mathrm{j}}$ are the flowing section area of the throat and the annular nozzle outlet, separately. $H$ and $Q$ represent the total pressure and flow rate. Subscripts $\mathrm{s}, \mathrm{j}$ and $\mathrm{c}$ represent the entrained, primary and mixed flow, respectively.

The experimental results (EXP.) in [15] and numerical results (NUM.) in Figure 5 were compared to verify the reliability of the numerical method. The mesh number was initially set as 35,000 (coarse mesh), which then increased the cell number in radial and axial directions, separately, and refined the mesh in the suction chamber. The mesh number was increased to 140,000 (medium mesh) and 260,000 (fine mesh). From Figure 5, it can be seen that there is an obvious difference between the results of coarse mesh and those of the experiment, while the difference between the results of other meshes and those of the experiment is negligible. Therefore, the medium mesh was adopted in this study to reduce the calculation cost.

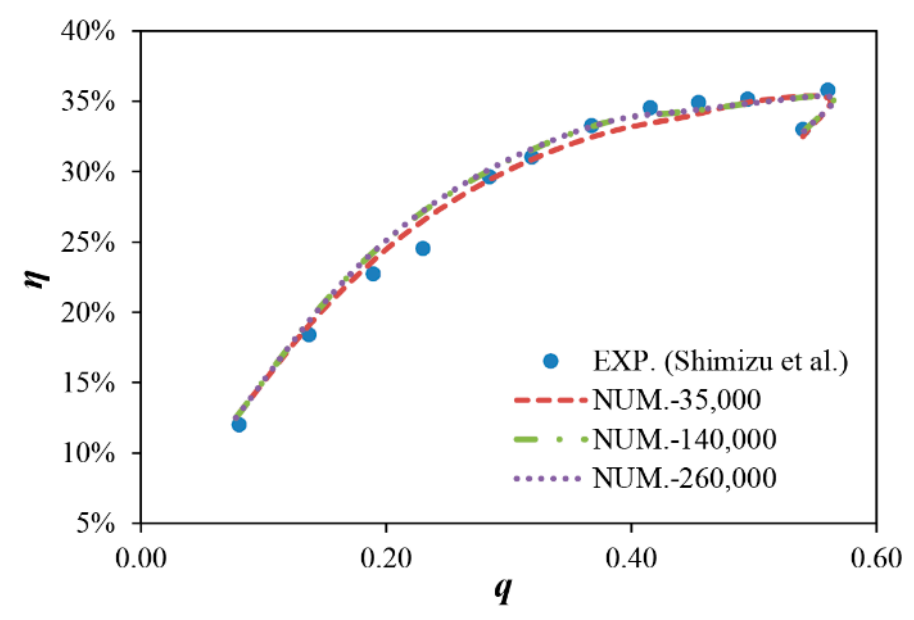

Figure 5. Comparison of the experimental and numerical results.

\section{Results and Discussion}

\subsection{Performance Curve}

Figure 6 depicts the performance curve of the EAJP and SAJP. Two pumps worked under the critical working condition when $q$ reached the maximum value. At this moment, $\eta$ and $h$ abruptly dropped with the decrease in outlet pressure $\left(p_{\mathrm{c}}\right)$, as shown in Figure 6. The maximum of $q$ was defined as the critical flow ratio $\left(q_{c}\right)$ of the jet pump when the jet pump worked at $q<q_{c}$, that is, the normal 
working condition of the jet pump, as shown in Figure 6b. Table 2 summarizes the comparison of the performance of two pumps based on Figure 6.

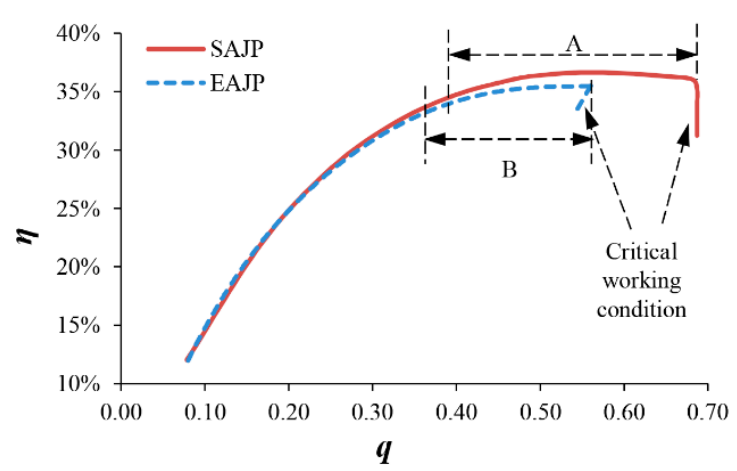

(a) Pump efficiency

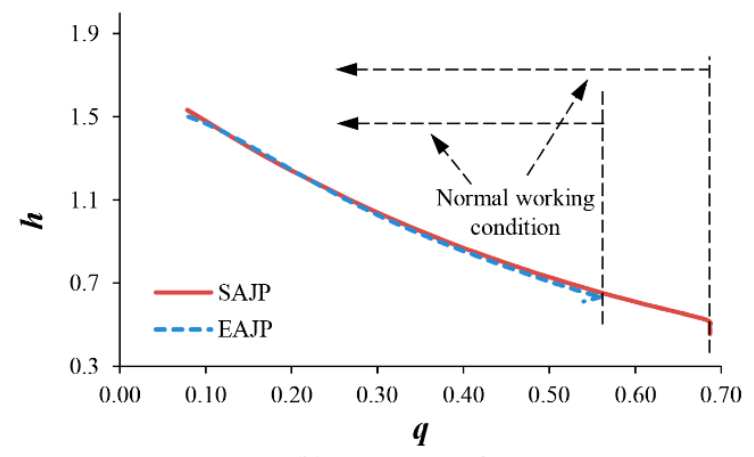

(b) Pressure ratio

Figure 6. Performance curves.

Table 2. Comparison of performance.

\begin{tabular}{ccccc}
\hline & $\eta_{\max }$ & High-Efficiency Area & $q_{c}$ & Normal Working Range \\
\hline EAJP & $36.0 \%$ & $q=0.36 \sim 0.57$ & 0.57 & $q<0.57$ \\
SAJP & $36.8 \%$ & $q=0.40 \sim 0.69$ & 0.69 & $q<0.69$ \\
\hline
\end{tabular}

The difference in $\eta$ of two pumps was negligible at $q<0.30$, while the $\eta$ of the SAJP was higher than that of the EAJP at $q>0.30$, and the maximum increase was $1.2 \%(q=0.53)$. Meanwhile, the difference in $h$ of the two pumps was obvious at $q>0.30$ and negligible at $q<0.30$. Additionally, the value of $q_{c}$ represents the range of normal working in the study of the jet pump, and the larger $q_{c}$ indicates the wider range of normal working. As shown in Figure $6 \mathrm{~b}, q_{c}$ of the EAJP and SAJP was 0.57 and 0.69 , separately, implying that the range of normal working of the SAJP was $21 \%$ wider than that of the EAJP. In this study, the working condition which efficiency was higher than $95 \% \eta_{\max }$ (maximum efficiency) was defined as the high-efficiency working condition. The high-efficiency areas of the EAJP and SAJP were $q=0.36 \sim 0.57$ and $q=0.40 \sim 0.69$, respectively, as shown in area A and B in Figure 6a. Hence, the high-efficiency area of the SAJP was wider than that of the EAJP.

\subsection{Pressure Distribution}

Figure 7 shows the wall pressure distribution at varied $q$. The pressure coefficient $\left(C_{\mathrm{p}}\right)$ was adopted to characterize the wall pressure distribution, as follows:

$$
C_{\mathrm{p}}=\left(p-p_{\mathrm{n}}\right) /\left(0.5 \rho u_{\mathrm{n}}^{2}\right)
$$

where $p$ is the static pressure, $u$ is the mean velocity and subscript $n$ represents the outlet of the annular nozzle.

In the EAJP, $C_{\mathrm{p}}$ had a drop at the inlet of throat and diffuser, due to the low local pressure in the center of the vortex which was caused by the flow separation. Notably, $C_{p}$ had a steeper drop at the throat inlet, because of the higher velocity of the primary flow near the throat wall. However, the primary flow could flow smoothly along the inner wall surface of the SAJP without the occurrence of flow separation, since the suction chamber, throat, diffuser and outlet pipe were smoothly connected in the SAJP. Therefore, no low local pressure appeared in the SAJP at varied $q$. 


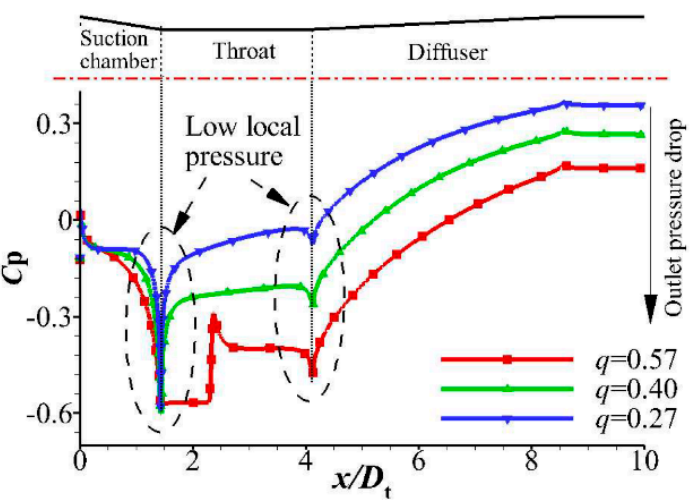

(a) EAJP

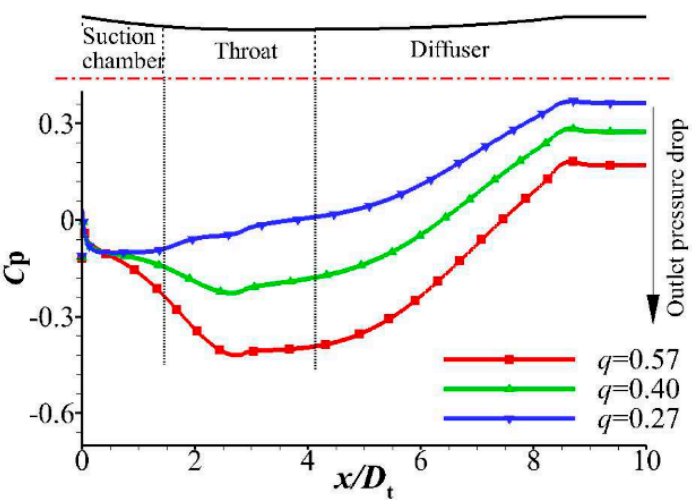

(b) SAJP

Figure 7. Wall pressure distribution.

Figure 8 depicts the pressure distribution at different $q$. The pressure in the two pumps decreased with the increasing $q$. From Figure 8 , it can be seen that there was a low local pressure near the wall of the throat inlet in the EAJP. The pressure in this area decreased obviously with the increase in $q$ and would induce cavitation. However, no low local pressure appeared in the SAJP at different $q$, as shown in Figure 8, that could improve its cavitation performance. The difference in the cavitation performance of the two pumps will be discussed in Sections 3.4 and 3.5 .

(a)
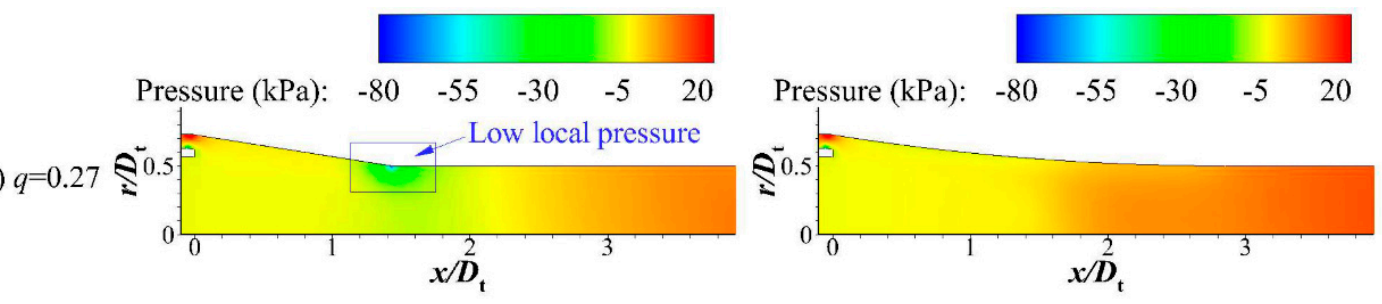

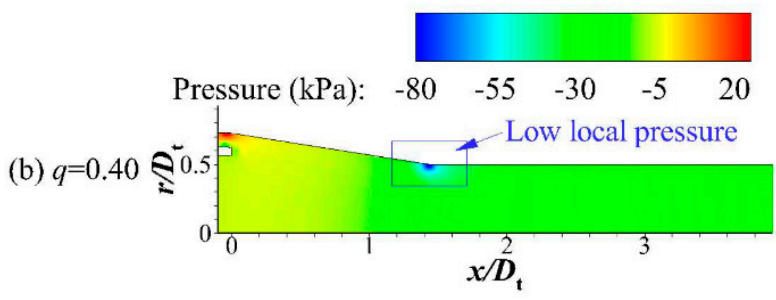

EAJP

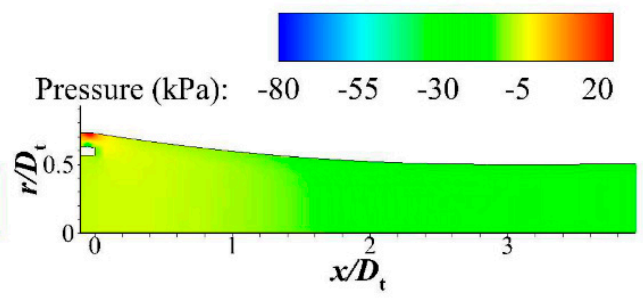

SAJP

Figure 8. Pressure distribution.

\subsection{Velocity Distribution}

Due to the difference between the EAJP and SAJP in inner the wall geometry, the velocity distribution in the two pumps was affected to some extent. The velocity distribution of the cross-section at $q=0.33$ is shown in Figure 9. The monitored surfaces in the two pumps were marked as (a-f), as shown in Figure 9. At the annular nozzle outlet $\left(x / D_{\mathrm{t}}=0.2\right.$, Figure 9a), the velocity distribution in the two pumps was approximately the same. At the upstream near the suction chamber inlet $\left(x / D_{\mathrm{t}}=1.0\right.$, Figure $9 b$ ), the velocity near the wall of the SAJP was slightly lower than that of the EAJP, because the diameter of the SAJP was larger than the EAJP at the same axial position, and the width of the flow field of entrained flow in the SAJP was wider than that in the EAJP. At the throat inlet $\left(x / D_{\mathrm{t}}=1.4\right.$, Figure $\left.9 \mathrm{c}\right)$, the difference of velocity distribution of the two pumps reached the maximum. The velocity near the wall of the EAJP was larger than that of the SAJP, and the width of the flow field of the entrained flow 
of the EAJP was narrower than that of the SAJP. Subsequently, the difference in velocity distribution decreased as the primary flow and entrained flow were gradually mixed, as shown in Figure 9d-f.

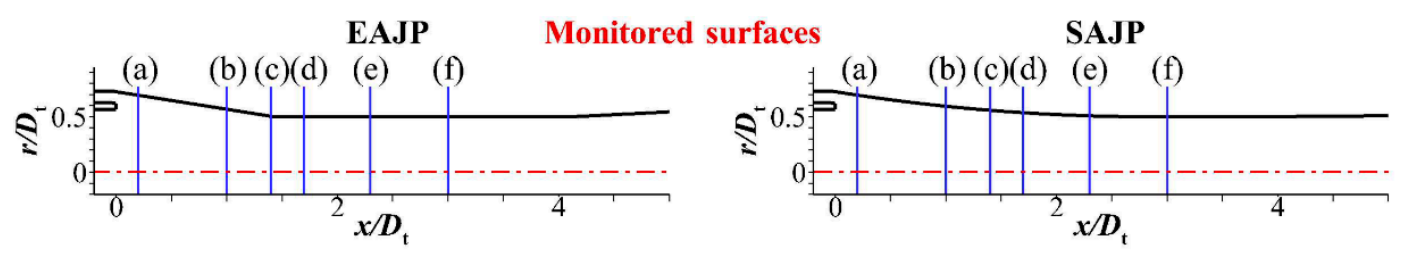

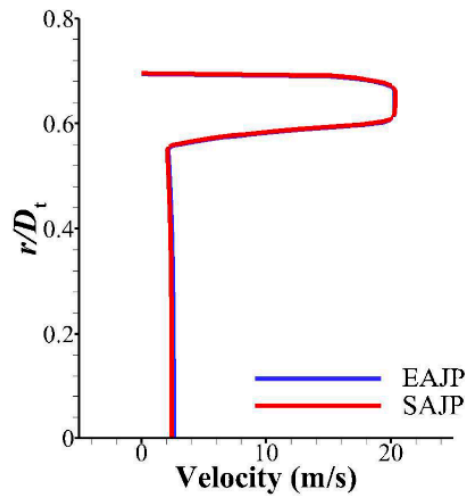

(a) $x / D_{\mathrm{t}}=0.2$

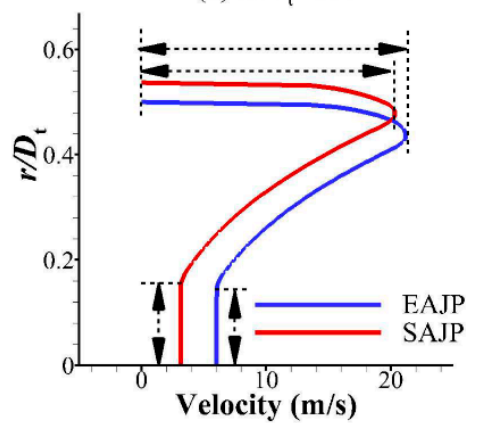

(d) $x / D_{\mathrm{t}}=1.7$

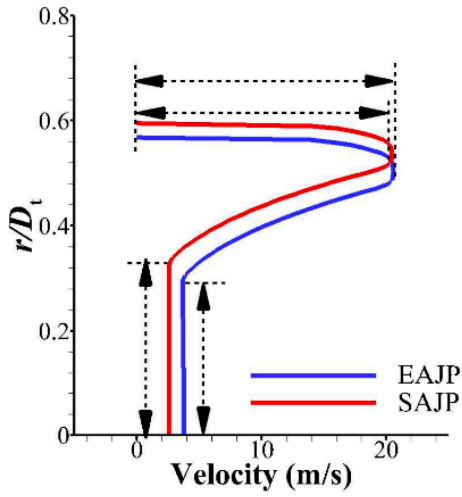

(b) $x / D_{\mathrm{t}}=1.0$

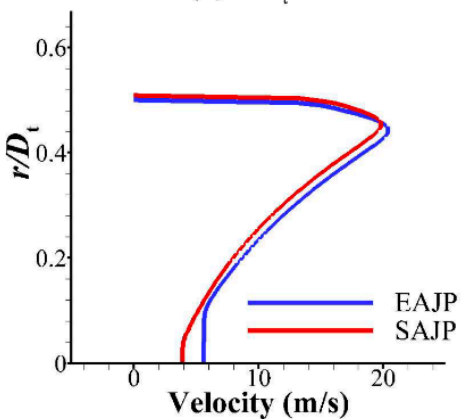

(e) $x / D_{\mathrm{t}}=2.3$

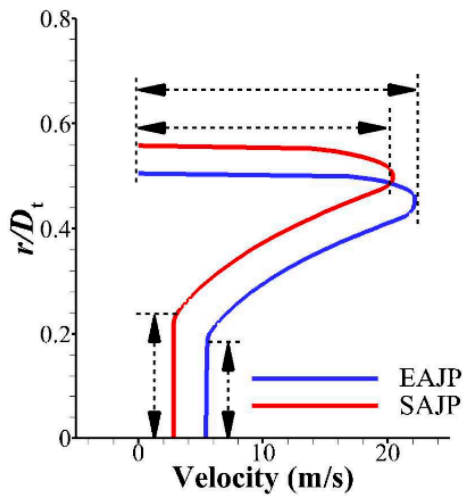

(c) $x / D_{\mathrm{t}}=1.4$

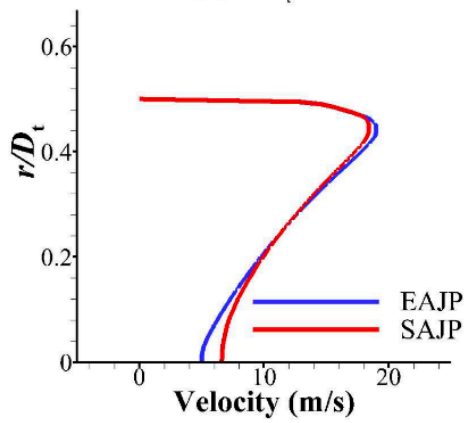

(f) $x / D_{t}=3.0$

Figure 9. Velocity distribution of the cross-section $(q=0.33)$.

Figure 10 depicts the velocity distribution at $q=0.33$ and 0.53 . From Figure 10, it can be seen that the length of the potential core of the primary flow in the EAJP was longer than that of the SAJP. Meanwhile, since the high-velocity primary flow usually flowed near the wall, the friction loss was greater, and the transport efficiency of pump was reduced. At $q=0.33$, the shapes of the flow field of the entrained flow in the two pumps were different. The length of the flow field of entrained flow in EAJP (to $x / D_{\mathrm{t}}=3.2$ ) was longer than that of the SAJP (to $x / D_{\mathrm{t}}=2.6$ ). Due to the abrupt structure change at the throat inlet of the EAJP, the primary flow had a more obvious tendency to flow toward the axis under the action of inertia, producing a compression effect on the flow field of entrained flow and leading to an increase in its length. However, in the SAJP, the compression effect of primary flow on the entrained flow field was negligible, and the entrained flow field was conical, as shown in Figure 10a. At $q=0.53$, the length and shape of the entrained flow field of the two pumps were approximately the same, as shown in Figure 10b. Besides, since the diameter of the SAJP was longer than that of the EAJP at the same axial position, the contact area between the primary and entrained flow in the SAJP was larger than that in the EAJP, improving the carrying capacity of the primary flow. 


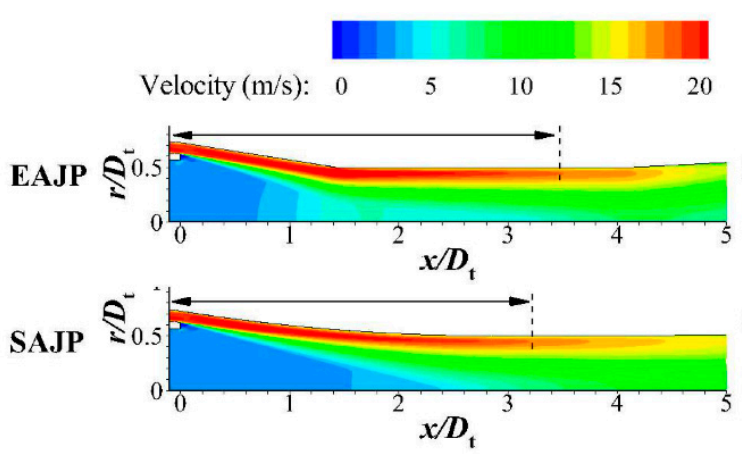

(a) $q=0.33$

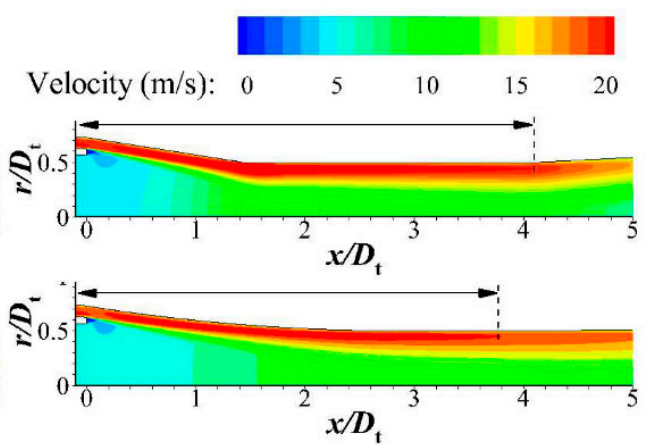

(b) $q=0.53$

Figure 10. Velocity distribution.

\subsection{Cavitation Inception}

The cavitation condition of the AJP involved many cavitation stages. The cavitation number $(\sigma)$ was adopted to describe the cavitation condition and defined as follows:

$$
\sigma=\left(p_{\mathrm{n}}-p_{v}\right) /\left(0.5 \rho u_{\mathrm{n}}^{2}\right)
$$

The working condition that some small bubbles generate near the wall of throat inlet is defined as the cavitation inception in the AJP, and the cavitation number at this moment is defined as the incipient cavitation number $\left(\sigma_{i}\right)$. In this study, the working condition that the vapor volume fraction reached $50 \%$ was defined as the cavitation inception.

It was found that the vapor volume fraction of the EAJP was $56.5 \%$ at $q=0.53$, implying that cavitation inception occurred at this moment. Figure 11 shows the pressure distribution and vapor volume fraction of the two pumps at $q=0.53$. From Figure 11a, it can be seen that the low local pressure area at the throat inlet of the EAJP was wider than that at lower $q$ and tended to expand toward the axis. At this time, cavitation inception occurred in the EAJP. The above phenomenon is consistent with the experimental result from Shimizu et al. [15]. However, no above low local pressure and cavitation appeared in the SAJP, as shown in Figure 11b. It was found that cavitation inception occurred in the SAJP at $q=0.68$, and the vapor volume fraction was $55.8 \%$ at this moment, as shown in Figure $12 \mathrm{~b}$. As the pressure in the SAJP was close to the saturated vapor pressure at $q=0.68$, cavitation occurred in the pump. Additionally, by comparing Figures 11a and 12, it can be found that the position of cavitation inception in the SAJP was at $x / D_{\mathrm{t}}=4.3$, which was closer to downstream than that in the $\operatorname{EAJP}\left(x / D_{\mathrm{t}}=1.4\right)$.

\subsection{Cavitation Development and Critical Working Condition}

After cavitation inception in the pump, cavitation continues to develop with the decrease in $p_{\mathrm{c}}$. When $p_{\mathrm{c}}$ drops to a certain value, the entrained flow ratio keeps constantly with the further decrease in $p_{c}$, and the pump reaches the critical working condition. Under the critical working condition, large numbers of cavity clouds generate and collapse in the pump. Consequently, the $\eta$ of the pump will decline sharply, and a strong vibration and noise will be produced $[25,26]$. The critical working condition restricts the normal working range of the jet pump, that is among the main obstacles to its popularization and application. Table 3 summarizes $q$ and $\sigma$ at varied $p_{\mathrm{c}}$. It can be found that $q$ kept increasing and $\sigma$ kept decreasing with the decrease in $p_{\mathrm{c}}$. Meanwhile, $\sigma$ kept constant when the pump worked under the critical working condition. Cavitation inception occurred in the EAJP at $p_{\mathrm{c}}=40 \mathrm{kPa}(q=0.53)$ with $\sigma_{i}=0.578$. However, cavitation inception occurred in the SAJP at $p_{\mathrm{c}}=19 \mathrm{kPa}$ ( $q=0.68)$ with $\sigma_{i}=0.541$, which was less than that of the EAJP, indicating that the SAJP displays a better cavitation performance than the EAJP. Besides, from Table 3, it can be seen that the EAJP reached the critical working condition at $p_{\mathrm{c}}=35 \mathrm{kPa}$, while the SAJP at $p_{\mathrm{c}}=15 \mathrm{kPa}$, implying that the EAJP is vulnerable to the critical working condition. 
(a) EAJP
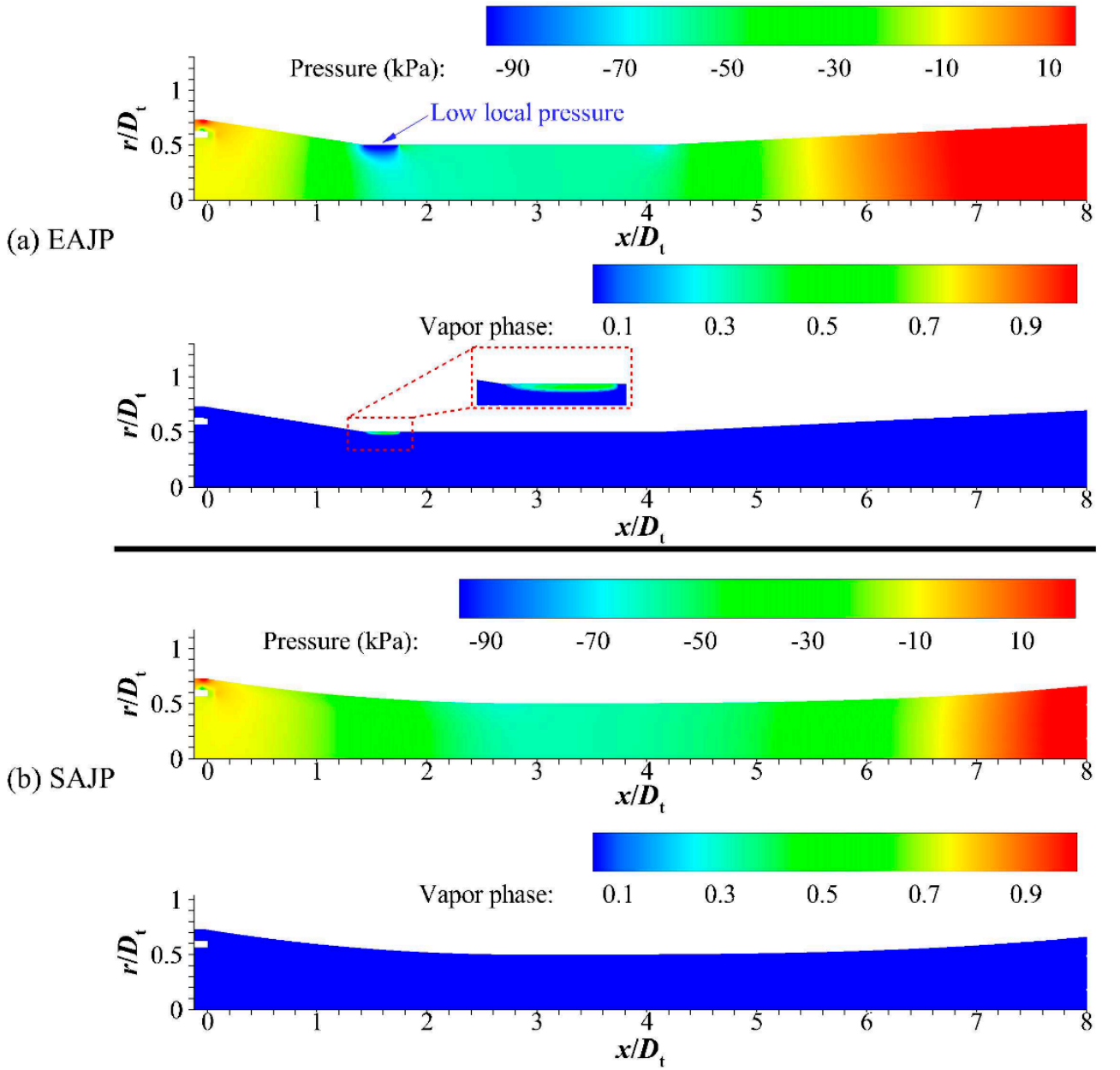

Figure 11. Pressure and vapor volume fraction distribution $(q=0.53)$.

(a)

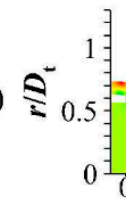

Pressure $(\mathrm{kPa})$ :

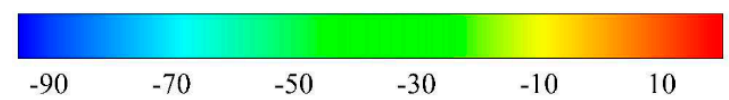

$0.5=$
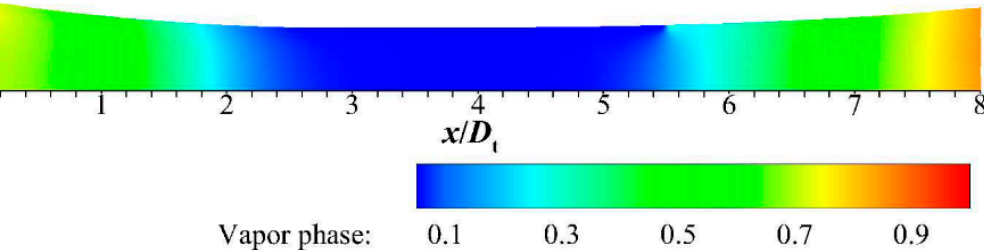

(b)

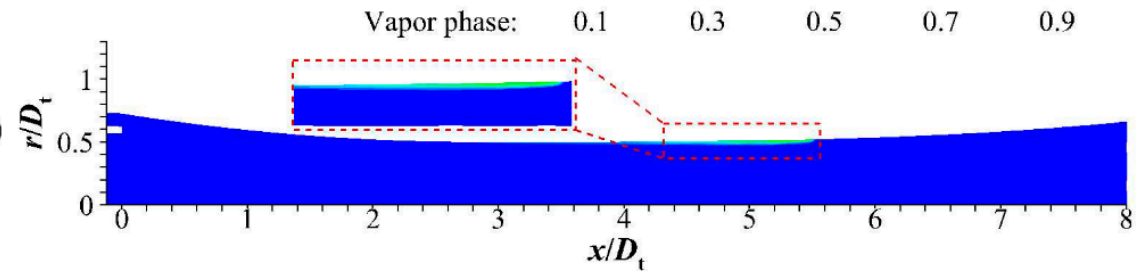

Figure 12. Pressure and vapor volume fraction distribution (SAJP, $q=0.68)$. (a) Pressure distribution; (b) Vapor volume fraction distribution. 
Table 3. Comparison of $q_{c}$ and $\sigma_{i}$.

\begin{tabular}{ccccccccc}
\hline & $\boldsymbol{p}_{\mathbf{c}} \mathbf{( k P a )}$ & $\mathbf{4 0}$ & $\mathbf{3 5}$ & $\mathbf{3 0}$ & $\mathbf{2 0}$ & $\mathbf{1 9}$ & $\mathbf{1 5}$ & $\mathbf{1 0}$ \\
\hline \multirow{2}{*}{$\boldsymbol{q}$} & EAR & 0.53 & $0.57\left(q_{c}\right)$ & 0.57 & 0.57 & 0.57 & 0.57 & 0.57 \\
& STR & 0.54 & 0.58 & 0.61 & 0.67 & 0.68 & $0.69\left(q_{c}\right)$ & 0.69 \\
$\sigma$ & EAR & $0.578\left(\sigma_{i}\right)$ & 0.571 & 0.571 & 0.571 & 0.571 & 0.571 & 0.571 \\
& STR & - & - & - & - & $0.541\left(\sigma_{i}\right)$ & 0.540 & 0.540 \\
\hline
\end{tabular}

Due to the different position of cavitation inception in the two pumps, the cavitation development process was also different. Figure 13 shows the cavitation development in the EAJP with the decreasing $p_{\mathrm{c}}$. As shown in Figure 13, cavitation initially occurred at the throat inlet of the EAJP at $p_{\mathrm{c}}=40 \mathrm{kPa}$ $(q=0.53)$. When $p_{\mathrm{c}}$ decreased to $35 \mathrm{kPa}(q=0.57)$, the EAJP reached the critical working condition, and the cavity cloud expanded toward the downstream of the throat. The moment that $p_{\mathrm{c}}$ further decreased to $30 \mathrm{kPa}(q=0.57)$, the cavity cloud suddenly expanded to the diffuser inlet.

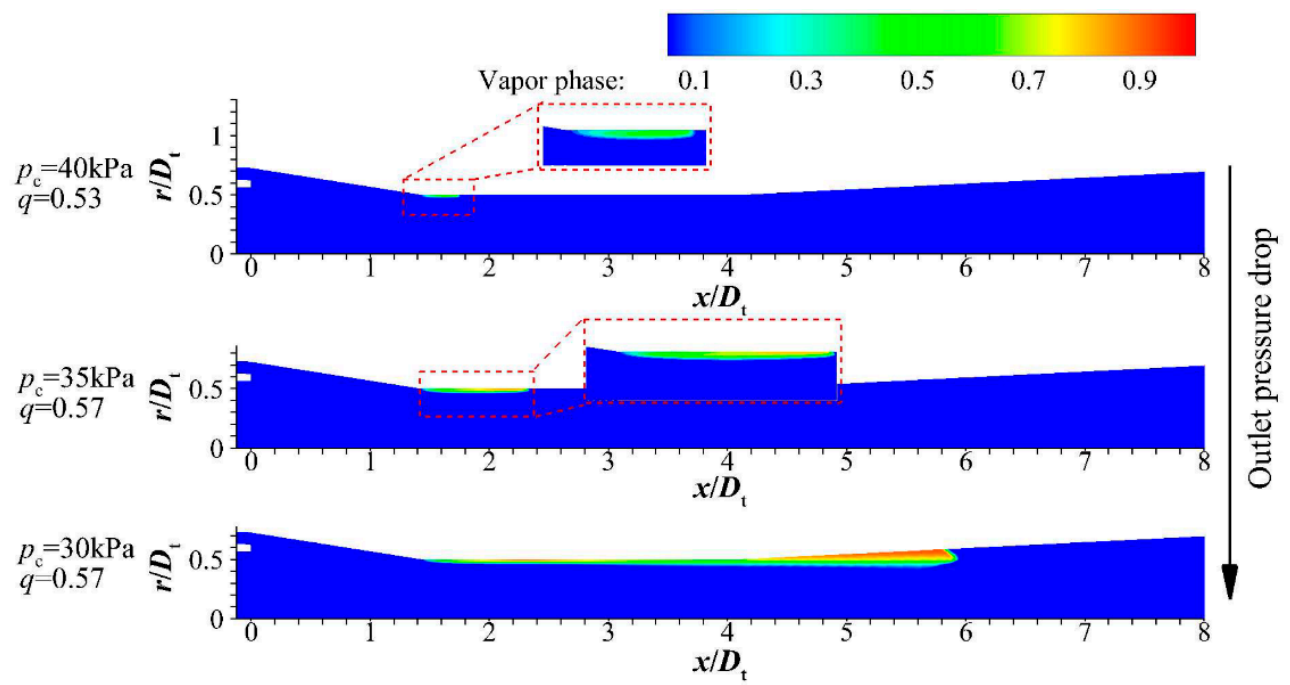

Figure 13. Cavitation development in the EAJP.

Figure 14 depicts the pressure and vapor volume fraction distribution in the SAJP at $q=0.57$. Different from the EAJP, which reached the critical working condition at the same $q$, no low local pressure appeared in the SAJP (Figure 14a). Moreover, since $q<0.68$ (the incipient cavitation flow rate of the SAJP), cavitation did not occur in the SAJP (Figure 14b). Figure 15 shows the cavitation development in the SAJP. Cavitation initially occurred at the diffuser inlet of the SAJP at $p_{\mathrm{c}}=19 \mathrm{kPa}$ $(q=0.68)$. When $p_{\mathrm{c}}$ decreased to $15 \mathrm{kPa}(q=0.69)$, the SAJP reached the critical working condition and the cavity cloud expanded toward the downstream of diffuser. The moment that $p_{\mathrm{c}}$ further decreased to $10 \mathrm{kPa}(q=0.69)$, the cavity cloud continued to expand. Since the mixing process of the primary and entrained flow is much fiercer in the suction chamber and throat than that in the diffuser, and is accompanied by a large velocity gradient and constant energy exchange, the cavitation in the EAJP had a significant impact on the mixing process. However, the mixing process was generally finished before entering the diffuser, and velocity in the diffuser was small and also more uniformly distributed. Therefore, the cavitation in the SAJP had relatively little impact on the performance and flow field of the jet pump. 
(a)

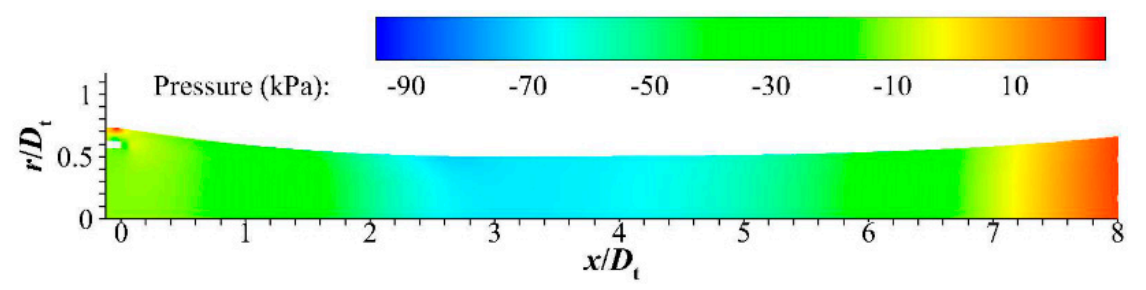

(b)

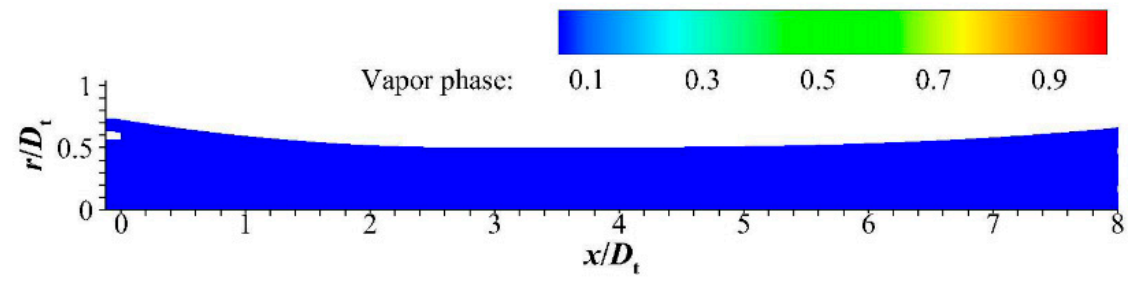

Figure 14. Pressure and vapor volume fraction distribution (STR, $q=0.57$ ). (a) Pressure distribution; (b) Vapor volume fraction distribution.

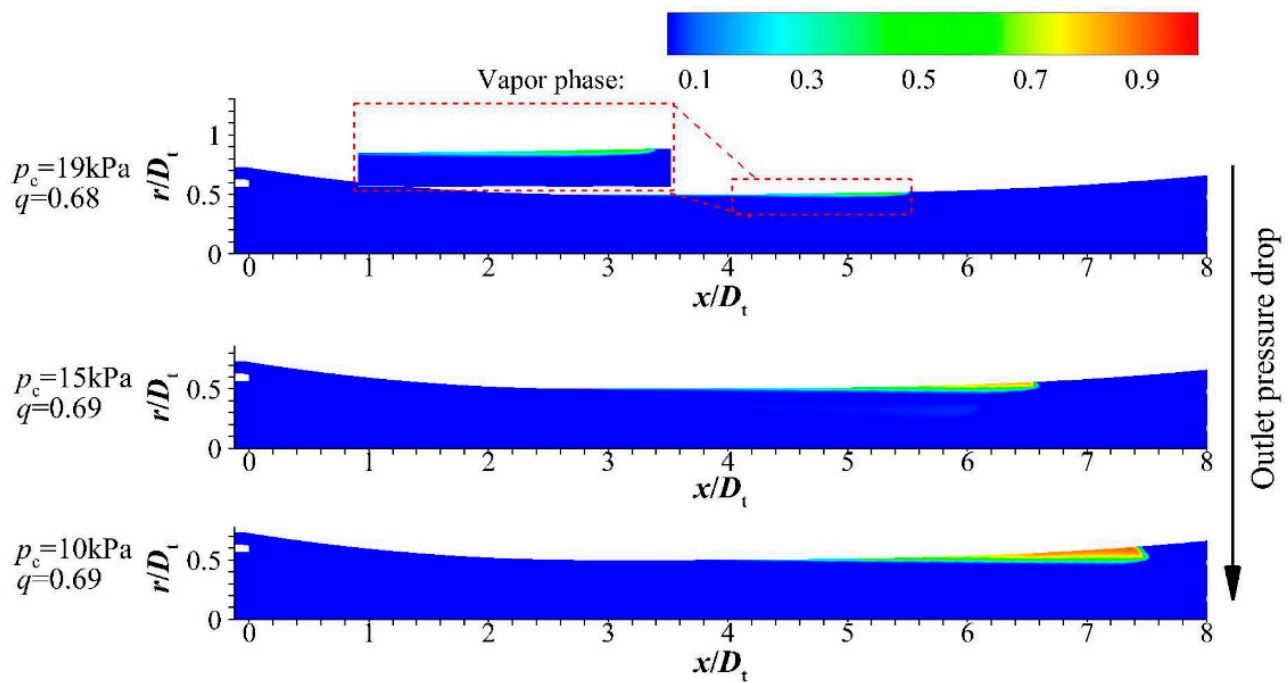

Figure 15. Cavitation development in the SAJP.

\section{Conclusions}

Since the high-velocity annular jet usually flows along the inner wall surface of the AJP, the geometry of the inner wall might have a significant impact on the tradition and cavitation performance of pump. To optimize the flow field of the EAJP, the SAJP was proposed to ensure that the high-velocity primary flow flowed smoothly in the pump, reducing the energy loss and avoiding the occurrence of low local pressure. The numerical simulation of the flow field in the EAJP and SAJP were carried out, separately, based on the numerical method which combined the Realizable $k-\varepsilon$ turbulence model and the Schnerr-Sauer cavitation model. The differences in traditional performance and cavitating flow of the two pumps were studied, and the results are as follows:

1. The efficiency $(\eta)$ of the SAJP is higher than that of the EAJP when $q>0.30$, and the maximum increase is $1.2 \%$ when $q=0.53$. However, the difference in efficiency is negligible when $q<0.30$.

2. The critical flow rate $\left(q_{c}\right)$ of the SAJP is 0.69 , which is larger than that of the EAJP $\left(q_{c}=0.57\right)$. Therefore, the range of normal working of the SAJP is $21 \%$ wider than that of the EAJP. Additionally, the high-efficiency areas of the SAJP and EAJP are $q=0.40 \sim 0.69$ and $q=0.36 \sim 0.57$, respectively, implying that the high-efficiency area of the SAJP is much wider. 
3. Since there is no abrupt change in the geometry of the SAJP, no low local pressure appears in the SAJP. The SAJP could normally work under a low outlet pressure without the cavitation occurrence. Meanwhile, the incipient cavitation number $\left(\sigma_{i}\right)$ of the SAJP is 0.541 , which is lower than that of the EAJP $\left(\sigma_{i}=0.578\right)$, showing a better cavitation performance.

4. There are differences in the position of cavitation inception and the process of cavitation development in the two pumps. In the EAJP, cavitation initially occurs at the throat inlet and develops in the throat, exerting a great impact on the flow field of pump. However, cavitation initially occurs at the diffuser inlet and develops in the diffuser of the SAJP. The position of cavitation inception and development in the SAJP are closer to the downstream than that in the EAJP. Therefore, the influence of cavitation on the flow field is less.

Author Contributions: X.W. performed the numerical simulations and was responsible for paper writing; Y.C. conceived the research and proposed the method; M.L. helped to analyze the results; Y.X. mainly contributed to the revision and improvement of the grammar and structure of the paper; B.W. provided guidance for numerical simulations and contributed to revising the paper; and X.D. provided recommendations for this research. All authors have read and agreed to the published version of the manuscript.

Funding: This work was supported by the National Natural Science Foundation of China (NSFC) (NO. 51879179 and 51709191).

Conflicts of Interest: The authors declare no conflict of interest.

\section{References}

1. Xu, M.; Ji, B.; Zou, J.; Long, X. Experimental investigation on the transport of different fish species in a jet fish pump. Aquac. Eng. 2017, 79, 42-48. [CrossRef]

2. Long, X.P.; Xu, M.S.; Wang, J.; Zou, J.L.; Ji, B. An experimental study of cavitation damage on tissue of Carassius auratus in a jet fish pump. Ocean Eng. 2019, 174, 43-50. [CrossRef]

3. Xu, M.S.; Long, X.P.; Mou, J.G.; Ji, B.; Ren, Y. Impact of fish locomotion on the internal flow in a jet fish pump. Ocean Eng. 2019, 187. [CrossRef]

4. Aus der Wiesche, S. Numerical simulation of cavitation effects behind obstacles and in an automotive fuel jet pump. Heat Mass Transf. 2005, 41, 615-624. [CrossRef]

5. Yin, P.; Hu, W.J.; Li, D.Y.; Li, X.Y.; Zeng, X.P. Application and Economic Analysis of Water Jet Pump in New District Heating System. Procedia Eng. 2017, 205, 996-1003. [CrossRef]

6. Liu, X.L.; Zhan, Q.Q.; Lia, Y.A. The application analysis of jet pump in heating system. Procedia Eng. 2017, 205, 2208-2214. [CrossRef]

7. Xu, M.S.; Long, X.P.; Mou, J.G.; Wu, D.H.; Zhou, P.J.; Gu, Y.Q. Impact of pressure gradients on fish scales in a jet fish pump. Biosyst. Eng. 2020, 191, 27-34. [CrossRef]

8. Long, X.P.; Xu, M.S.; Lyu, Q.; Zou, J.L. Impact of the internal flow in a jet fish pump on the fish. Ocean Eng. 2016, 126, 313-320. [CrossRef]

9. Xiao, L.Z.; Long, X.P.; Li, L.; Xu, M.S.; Wu, N.; Wang, Q.Q. Movement characteristics of fish in a jet fish pump. Ocean Eng. 2015, 108, 480-492. [CrossRef]

10. Dong, J.; Qian, Z.D.; Thapa, B.S.; Thapa, B.; Guo, Z.W. Alternative Design of Double-Suction Centrifugal Pump to Reduce the Effects of Silt Erosion. Energies 2019, 12, 158. [CrossRef]

11. Pei, J.; Zhang, F.; Appiah, D.; Hu, B.; Yuan, S.Q.; Chen, K.; Asomani, S.N. Performance Prediction Based on Effects of Wrapping Angle of a Side Channel Pump. Energies 2019, 12, 139. [CrossRef]

12. Kwon, O.B.; Kim, M.K.; Kwon, H.C.; Bae, D.S. Two-dimensional numerical simulations on the performance of an annular jet pump. J. Vis.-Jpn. 2002, 5, 21-28. [CrossRef]

13. Long, X.P.; Zeng, Q.L.; Yang, X.L.; Xiao, L. Structure optimization of an annular jet pump using design of experiment method and CFD. In Proceedings of the IOP Conference Series: Earth and Environmental Science, Putrajaya, Malaysia, 5-6 March 2013. [CrossRef]

14. Yang, X.; Long, X.; Kang, Y.; Xiao, L. Application of Constant Rate of Velocity or Pressure Change Method to Improve Annular Jet Pump Performance. Int. J. Fluid Mach. Syst. 2013, 6, 137-143. [CrossRef]

15. Shimizu, Y.; Nakamura, S.; Kuzuhara, S.; Kurata, S. Studies of the Configuration and Performance of Annular Type Jet Pumps. J. Fluids Eng. 1987, 109, 205-212. [CrossRef] 
16. Xiao, L.Z.; Long, X.P.; Wu, W.; Yan, H.F.; Kang, Y. Numerical investigation on the impact of the converging angle of the suction chamber on annular jet pumps. In Proceedings of the IOP Conference Series: Materials Science and Engineering, Kuala Lumpur, Malaysia, 2-4 July 2013. [CrossRef]

17. Xiao, L.; Long, X. Cavitating flow in annular jet pumps. Int. J. Multiph. Flow 2015, 71, 116-132. [CrossRef]

18. Xiao, L.Z.; Long, X.P.; Zhang, J.Q. Shear Cavitation in an Annular Jet Pump under Recirculation Conditions. J. Fluids Eng. 2016, 138. [CrossRef]

19. Wang, X.D.; Chen, Y.L.; Zhao, Y.; Xu, Y.; Wang, B. Influence of suction chamber profile on flow field of annular jet pump. In Proceedings of the IOP Conference Series: Earth and Environmental Science, Milan, Italy, 4-5 September 2019. [CrossRef]

20. Xiao, L.Z.; Long, X.P.; Lyu, Q.; Hu, Y.; Wang, Q.Q. Numerical investigation on the cavitating flow in Annular Jet Pump under different flow rate ratio. In Proceedings of the IOP Conference Series: Earth and Environmental Science, Jakarta, Indonesia, 23-24 January 2014. [CrossRef]

21. Xiao, Q.; Wang, J.R.; Zhao, Z.X.; Bai, F.; Wei, Z.G.; Li, S.D. Numerical Simulation of the Cavitation Flow inside the Jet Pump. In Proceedings of the 25th International Conference on Nuclear Engineering, Shanghai, China, 2-6 July 2017.

22. Xiao, L.Z.; Long, X.P. Influence of inclined angle on cavitation performance of annular jet pump. J. Zhejiang Univ. Eng. Sci. (China) 2018, 49, 123-129. [CrossRef]

23. Rayleigh, L. VIII. On the pressure developed in a liquid during the collapse of a spherical cavity. Lond. Edinb. Dublin Philos. Mag. J. Sci. 1917, 34, 94-98. [CrossRef]

24. Xu, M.S.; Yang, X.L.; Long, X.P.; Lyu, Q.; Ji, B. Numerical investigation of turbulent flow coherent structures in annular jet pumps using the LES method. Sci. China Ser. E Technol. Sci. 2018, 61, 86-97. [CrossRef]

25. Zhu, X.L.; Wang, D.M.; Xu, C.H.; Zhu, Y.F.; Zhou, W.D.; He, F. Structure influence on jet pump operating limits. Chem. Eng. Sci. 2018, 192, 143-160. [CrossRef]

26. Long, X.; Yao, H.; Zhao, J. Investigation on mechanism of critical cavitating flow in liquid jet pumps under operating limits. Int. J. Heat Mass Transf. 2009, 52, 2415-2420. [CrossRef]

(C) 2020 by the authors. Licensee MDPI, Basel, Switzerland. This article is an open access article distributed under the terms and conditions of the Creative Commons Attribution (CC BY) license (http://creativecommons.org/licenses/by/4.0/). 